https://doi.org/10.1590/198053145992

\title{
RESISTÊNCIA E RESIGNAÇÃO: NARRATIVAS DE GÊNERO NA ESCOLHA POR ENFERMAGEM E PEDAGOGIA ${ }^{1}$
}

\author{
Renata Mourão Macedo'
}

\section{Resumo}

$O$ artigo analisa narrativas de estudantes universitárias dos cursos de Enfermagem e Pedagogia em duas faculdades privadas em São Paulo (SP), a partir de pesquisa de cunho etnográfico. Em especial, focaliza as narrativas de gênero (articulado com classe social e idade), elucidando como as próprias estudantes percebem suas escolhas. No caso do ingresso no curso de Enfermagem, evidenciam-se relatos sobre as dificuldades de cursar Medicina, por um lado, e as expectativas de ultrapassar o nível técnico ou ter uma profissão com reconhecimento social, por outro. Já no caso de Pedagogia, trata-se do desafio de conciliar a aptidão para o trabalho docente com os aspectos pragmáticos, diante de um curso mais acessível, embora pouco valorizado. Em ambas as carreiras, os processos de feminização dessas áreas se produzem e reproduzem por meio de associações persistentes entre feminilidade e cuidado.

\section{ESCOLHA PROFISSIONAL • ENSINO SUPERIOR • GÊNERO • ESTUDANTES UNIVERSITÁRIOS}

\section{RESISTANCE AND RESIGNATION: GENDER NARRATIVES IN THE CHOICE OF NURSING AND EDUCATION}

\section{Abstract}

This article analyzes narratives of undergraduate students, enrolled in Nursing and Pedagogy programs at two private colleges in São Paulo (SP), based on an ethnographic research. In particular, it focuses on gender narratives (articulated with social class and age), elucidating how the students themselves perceive their choices. In the case of admission to the Nursing program, there are reports about the difficulties of getting into the Medicine program, on the one hand; and, the expectations of exceeding the technical level, or having a profession with social recognition, on the other. In the case of Pedagogy, it deals with the challenge of reconciling the aptitude for teaching with the pragmatic aspects, in view of a more accessible, although little appreciated, program. In both careers, the processes of feminization of these areas are produced and reproduced through persistent associations between femininity and care.

\section{PROFESSIONAL CHOICE • HIGHER EDUCATION • GENDER RELATIONS • UNIVERSITY STUDENT}

1 Uma versão inicial e resumida deste texto foi apresentada e publicada nos Anais do XI Seminário Internacional Fazendo Gênero, em 2018, sob o título Narrativas de gênero na escolha por enfermagem e pedagogia: expectativas de estudantes mulheres no sistema privado de ensino superior.

A presente pesquisa foi realizada com apoio da Coordenação de Aperfeiçoamento de Pessoal de Nível Superior (Capes) - Código de Financiamento 001.

I Universidade de São Paulo (USP), São Paulo (SP), Brasil; https://orcid.org/0000-0002-2807-4605; renatagmourao@hotmail.com 


\section{RÉSISTANCE ET RÉSIGNATION: RÉCITS DE GENRE SUR LE CHOIX DES DIPLÔMES EN SOINS INFIRMIERS ET EN PÉDAGOGIE}

\section{Résumé}

Cet article analyse des récits d'étudiantes universitaires de deux facultées privées à São Paulo (SP). Il s'agit d'une recherche ethnographique qui se concentre plus particulièrement sur les récits de genre (s'articulant à l'âge et à la classe sociale). Ce travail cherche à élucider comment les étudiants perçoivent eux mêmes leurs choix. Dans le cas de l'admission à l'école d'infirmiers, on observe que les témoignages abordent d'un côté la question des difficultés d'admission en faculté de médecine et de l'autre côté les attentes de dépasser le niveau technique ou d'avoir une profession reconnue socialement. Pour ce qui est de la Pédagogie, il s'agit du défi de concilier une aptitude pour l'enseignement à des questions plus pragmatiques, puisque ce cours est plus accessible, bien que moins valorisé socialement. Dans les deux carrières, il existe des processus de féminisation qui se produisent e $t$ se reproduisent par le biais d' associations persistantes entre féminité et soins.

\section{CHOIX PROFESSIONNEL • ENSEIGNEMENT SUPÉRIEUR • GENRE • ÉTUDIANTS UNIVERSITAIRES}

\section{RESISTENCIA Y RESIGNACIÓN: NARRATIVAS DE GÉNERO EN LA ELECCIÓN POR ENFERMERÍA Y PEDAGOGÍA}

\section{Resumen}

El artículo analiza narraciones de estudiantes universitarios de los cursos de Enfermería y pedagogía en dos facultades privadas en São Paulo (SP), a partir de la investigación de naturaleza etnográfica. En especial, focaliza las narrativas de género (articulado con clase social y edad), elucidando como las propias estudiantes perciben sus elecciones. En el caso de ingreso al curso de Enfermería, se evidencian relatos sobre las dificultades de cursar Medicina, por un lado, y las expectativas de ultrapasar el nivel técnico o tener una profesión con reconocimiento social, por otro. Ya en el caso de pedagogía, se trata del reto de conciliar la aptitud para el trabajo docente con los aspectos pragmáticos, delante de un curso más accesible, aunque poco valorizado. En ambas carreras, los procesos de feminización de esas áreas se producen y reproducen por medio de asociaciones persistentes entre feminidad y el cuidado.

\section{ELECCIÓN PROFESIONAL • EDUCACIÓN SUPERIOR • GÉNERO • ESTUDIANTES UNIVERSITARIOS}


Nós da enfermagem gostamos de gente, nós estudamos para cuidar de gente. E somos quase só mulheres na sala, hein? [...] Os médicos não, eles estudam para cuidar de patologias, de doenças. E a maioria deles gosta muito de dinheiro, se movem por isso, nós não. (Amanda, estudante de Enfermagem)

OS ESQUEMAS CLASSIFICATÓRIOS ENTRE CURSOS DE ENSINO SUPERIOR, DIPLOMAS e instituições, constroem-se hierarquias segundo critérios de prestígio, status e rendimentos no mercado de trabalho. Nessas classificações, permanentemente feitas e refeitas por rankings educacionais, mídia, instituições de ensino, mercado e pelos próprios estudantes, alguns grupos profissionais "valem mais" enquanto outros "valem menos". Entre os marcadores sociais da diferença que produzem tais hierarquias, gênero certamente ainda é uma categoria constitutiva de tais desigualdades.

Em meio a tais disputas classificatórias, no momento de fazer escolhas para entrada no ensino superior, estudantes orientam-se conforme os repertórios mais ou menos amplos adquiridos em suas trajetórias, enfrentado diversas dúvidas: Se eu seguir nesse curso, vou ter emprego quando formada? Terei espaço para trabalhar com o que gosto? Ganharei dinheiro? Ficarei rica? Serei realizada? Mais vale um curso de menor prestígio em uma faculdade de qualidade ou um curso mais disputado em uma faculdade de menor status? Conforme pesquisa de campo realizada entre 2015 e 2018 com mulheres jovens e adultas de baixa renda, estudantes em duas faculdades privadas não confessionais na região metropolitana de São Paulo, essas são algumas das dúvidas que perpassam a entrada no ensino superior.

Nessas classificações, enquanto no Brasil o curso de Medicina tem se constituído historicamente como um dos mais prestigiosos, conciliando status e 
expectativas de altos rendimentos no mercado de trabalho (bastante superiores à média nacional), ${ }^{2}$ os cursos de Pedagogia (licenciatura) e Enfermagem (bacharelado), analisados neste artigo, não têm o mesmo prestígio nesse sistema classificatório. No entanto, ambos os cursos estão entre os dez maiores do Brasil, atraindo anualmente milhares de estudantes, em sua maioria mulheres, revelando persistente tendência de feminização. ${ }^{3}$ Apenas em 2015 foram 655.813 mil estudantes matriculados em Pedagogia (sendo 92\% mulheres), constituindo-se como o terceiro maior curso superior do país, e 261.215 mil matriculados em Enfermagem (sendo 85\% mulheres), listado como o sexto maior curso superior brasileiro (BRASIL, 2015). ${ }^{4}$

Conforme a estudante de enfermagem Amanda ${ }^{5}$ explicitou na fala do início deste artigo, delineiam-se disputas entre cursos, instituições e estudantes. No caso de Amanda, sua fala de resistência buscava reposicionar o curso de Enfermagem em tais classificações, em oposição aos estudantes de Medicina, considerados por ela como "mais focados em dinheiro". Enfermagem, ao contrário, concentraria estudantes - mulheres, em especial - interessados, segundo ela, no que mais importa: cuidar de pessoas. De acordo com o que argumentou Amanda nessa entrevista: "sinceramente, Medicina e Enfermagem são coisas bem distintas. Eu nem que tivesse tempo e dinheiro, eu não faria Medicina”.

Em uma das conversas que tive com Amanda e duas amigas do curso de Enfermagem, em uma lanchonete localizada próximo à sua faculdade, na região central de São Paulo, Amanda discordava de uma de suas amigas, Ana Luisa, ${ }^{6}$ que me contava que escolhera Enfermagem, mas "o verdadeiro sonho" era cursar Medicina. Nesse diálogo, ao debater com elas o tema de minha pesquisa e meu interesse em acompanhá-las ao longo do curso, discutíamos também as possíveis diferenças entre estudantes de diferentes áreas, segundo sistemas classificatórios "nativos" sobre cursos superiores e seus diplomas.

Ana Luisa: Eu acho que se for para comparar, acho que os estudantes de Direito são bem inteligentes, gostam muito de estudar...

2 Segundo pesquisa realizada pelo Instituto de Pesquisa Econômica Aplicada (Ipea) em 2013, Medicina era o curso que garantia maiores rendimentos, calculados a R \$ 8.459, em média. Comparativamente, os salários da área de Educação foram calculados como sendo, em média, R\$2.420 e em Enfermagem, em média, R\$3.495 (IPEA, 2013 ).

3 De modo relevante para a reflexão apresentada neste artigo, Silvia Yannoulas (2011) pontua diferenças entre as noções de feminização e feminilização. Conforme sua interpretação, enquanto a feminilização seria resultante de um processo quantitativo de aumento de mulheres em determinada atividade profissional, a feminização seria um passo além, revelando mudanças qualitativas de significados e perda de valor social, decorrentes da feminilização.

4 Conforme o censo da Educação Superior de 2015, os dez cursos com maiores números de matrícula no Brasil foram: Direito (853 mil estudantes matriculados), Administração (766 mil), Pedagogia ( 655 mil), Ciências Contábeis (358 mil), Engenharia Civil (355 mil), Enfermagem (261 mil), Psicologia (223 mil), Recursos Humanos (177 mil), Serviço Social (172 mil) e Engenharia da Produção (170 mil). Juntos tais cursos concentram 49,8\% das matrículas no ensino superior (BRASIL, 2015).

5 Amanda, 25 anos, viúva, sem filhos, autodeclarada negra. Concluiu o curso Técnico de Enfermagem, mas no período dessas conversas estava desempregada.

6 Ana Luisa, 24 anos, solteira, sem filhos, autodeclarada parda. No período dessas conversas trabalhava como Técnica de Enfermagem em um grande hospital privado na capital paulista. 
Amanda: Mas na maioria das vezes alguém da familia já é da área, pode ver, tem um pai ou um tio que já está na carreira, já é advogado, e acaba influenciando o filho [...].

Pesquisadora: $E$ as estudantes de Pedagogia?

Amanda: Acho que é um profissional que gosta do que faz. Acho que nesse sentido é próximo da gente de Enfermagem, acho que gosta do que faz, tem que ter paciência, tem que ter vontade de aprender.

Ana Luisa: Acho que na Pedagogia tem que ter amor de verdade para cuidar de criança.

Amanda: E tem que ser desapegado de bens materiais, porque o salário não é bom. Você não ganha bem [Ana concorda: "é sim, é mal remunerado"], você passa nervoso. Tem que ter amor à profissão!

Ana Luisa: É mesmo, é que nem a gente da Enfermagem, tem que ter amor! [risos]

Em tais classificações delineadas nessa conversa, enquanto estudantes de Medicina, Direito e Administração apareciam como afastados da visão de mundo e dos interesses que elas apresentavam, as estudantes de Pedagogia eram imaginadas como próximas, igualmente dedicadas a saberes considerados importantes, mas desvalorizados, movidas por ideais como "amor" e dedicação aos conhecimentos e às atividades desempenhadas.

Conforme é possível observar em tais imaginários sobre cursos, estudantes e o valor no mercado de trabalho para cada área, também se entrelaçam a todo momento percepções sobre posição social e expectativas de mobilidade social. Nessa conversa, a estudante Ana Luisa completava:

Acho que, pelo menos aqui na nossa faculdade, o curso de Enfermagem atrai mais uma classe média baixa, ou mesmo alunos de menor renda... As ricaças vão fazer outra coisa! Estão na Odontologia, na Medicina.

Ana se referia, especificamente, aos cursos de Odontologia e de Medicina oferecidos na mesma faculdade e que claramente são voltados para um outro perfil social: enquanto elas pagavam no ano de 2016 uma mensalidade de cerca de R 500 para estudar Enfermagem, o curso de Medicina era oferecido por uma mensalidade de R\$ 7 mil. Ou seja, para além de diferenças simbólicas, diferenças econômicas apontavam para um intenso processo de estratificação entre esses dois cursos na mesma instituição de ensino superior (IES), que reunia, assim, um público bastante heterogêneo. Tais distanciamentos sociais também se faziam presenciais, de modo que turmas de diferentes cursos "não se misturam": “a gente nunca conversou com ninguém de Medicina, eles até vão para outro barzinho de sexta-feira”, contavam as estudantes de enfermagem nessa conversa. 
De fato, além das desigualdades nas trajetórias escolares e no acesso ao ensino superior, segundo Ribeiro e Schlegel (2015), verifica-se também um expressivo fenômeno de "estratificação horizontal” entre cursos e instituições no ensino superior brasileiro, marcado por importantes cortes de gênero, classe e cor/etnia entre as carreiras. Na pesquisa realizada pelos autores a partir de censos brasileiros entre 1960 e 2010, quando observados os retornos financeiros dos profissionais formados, verificou-se um contraste expressivo entre as duas pontas do sistema universitário brasileiro: do lado superior, Medicina, com o maior salário médio; na ponta inferior, Pedagogia, apresentando os piores rendimentos.

Neste artigo, analiso narrativas sobre o processo de escolha dos estudos superiores, focalizando as experiências de estudantes mulheres matriculadas nos cursos de Enfermagem e Pedagogia em duas instituições privadas de ensino superior na cidade de São Paulo. Após descrever brevemente a realização da pesquisa de campo de cunho etnográfico, discuto os dilemas envolvidos, segundo as estudantes, na escolha dos cursos de Enfermagem e Pedagogia, e como narrativas de gênero permeiam tais escolhas. Conforme a fala de Amanda citada anteriormente revela, as estudantes também debatem tais hierarquias e buscam se posicionar diante delas. Na pesquisa realizada, procurei dar ênfase às narrativas e imaginários estabelecidos pelas próprias estudantes nesses processos de decisão. O objetivo, assim, foi visibilizar a sobreposição de "narrativas pragmáticas” com "narrativas vocacionais", evidenciando um esforço por parte das estudantes de fugir das armadilhas de uma régua única que mediria o sucesso escolar e profissional como exclusivamente voltado aos rendimentos financeiros.

\section{A PESQUISA DE CAMPO: CONVERSANDO COM ESTUDANTES SOBRE ESCOLHAS}

Inspirada em trabalhos de cunho mais etnográfico sobre processos educativos realizados na Antropologia e na Sociologia, que trazem um olhar aproximado sobre estudantes e suas negociações cotidianas (PEREIRA, 2017; LAHIRE, 2004; WILLIS, 1991), a pesquisa de campo foi realizada a partir de conversas e entrevistas com 21 estudantes universitários de duas IES privadas em São Paulo entre 2015 e 2018. Foram selecionados três cursos - Enfermagem, Pedagogia e Administração - e duas instituições privadas de ensino superior, que aqui chamarei de Faculdade 1 e Faculdade $2 .^{7}$ Complementando essa parte da pesquisa, entre 2016 e 2017 também participei por algumas semanas de grupos de WhatsApp das turmas de ingressantes dos cursos de Enfermagem e Pedagogia de uma dessas instituições, além de acompanhar algumas interações nas redes sociais. ${ }^{8}$ Nos primeiros dias

\footnotetext{
7 A Faculdade 1 está em uma região central da cidade de São Paulo, próximo a estações de metrô. Concentra, assim, um público mais heterogêneo socialmente do que a Faculdade 2, localizada na região de Taboão da Serra/bairro de Campo Limpo, zona sudoeste da região metropolitana de São Paulo. Se na Faculdade 2 um dos motivos de escolha da instituição (além do preço) era a proximidade com a residência, na Faculdade 1 a proximidade com o trabalho se destacou.

8 Sobre a realização de pesquisa de campo on-line e a disseminação das tecnologias comunicacionais em rede, ver Miskolci (2016).
} 
de aula de cada turma, minha apresentação também como estudante (ainda que de pós-graduação e da USP), interessada em realizar pesquisa universitária sobre escolhas e experiências no ensino superior, favoreceu o interesse por parte dessas estudantes para refletir sobre tais temas e contribuir para o presente trabalho.

Levando em conta o campo de possibilidades em transformação (VELHO, 2013), dada a organização atual do sistema universitário brasileiro e paulistano, cumpre destacar como o ensino superior passou por um importante processo de expansão recentemente, em especial entre 2005 e 2015. Nesse processo, destacou-se o grande crescimento do sistema privado, indicando um forte processo de privatização e mercantilização dessa etapa de ensino no Brasil, abocanhando em 2016 cerca de 75\% das matrículas (BRASIL, 2016). Assim, paralelo ao processo de inclusão e democratização do ensino superior no período, conquistado por meio de contínuas lutas políticas e sociais (consolidando, por exemplo, a implementação da Lei de Cotas para universidades federais, em 2012), deu-se também um processo de massificação do ensino superior, em que se destacou o setor privado não confessional, com ou sem fins lucrativos. Esse processo vem crescendo em parte por interesse do mercado em absorver a demanda de estudantes que não conseguem ingressar em universidades públicas ou privadas confessionais, em parte subsidiado pelo governo federal, especialmente alavancados por políticas como o Programa Universidade para Todos (ProUni) e o Fundo de Financiamento Estudantil (Fies) desde meados dos anos 2000 (SAMPAIO, 2014; ALMEIDA, 2015; COSTA, 2015).

Nesse contexto, meu olhar destaca a experiência de mulheres que ingressaram no ensino superior nesse período, focalizando especialmente uma fração de classe que recentemente esteve no centro do debate brasileiro sobre classes sociais, ficando conhecida como "nova classe trabalhadora", "nova classe média" ou, pela linguagem economicista de mercado, “classe C” (KOPPER; DAMO, 2018). Contudo, de minha parte, essas disputas classificatórias também são objeto de análise. Não utilizei a priori qualquer critério socioeconômico para delimitar quem faria ou não parte da pesquisa de campo. Meu interesse recaiu justamente nas narrativas cotidianas sobre os marcadores sociais da diferença, gênero e classe social em especial, observando o modo como tais categorizações são "negociadas" no cotidiano de tais estudantes, orientando ou não suas escolhas.

Com a crise socioeconômica e política que impactou o país a partir de 2015, resultando na estagnação das matrículas no setor privado de educação superior (SALDAÑA; BOLDRINI, 2017), as perspectivas para o mercado de trabalho pioraram e o desemprego aumentou, complexificando a análise. Tratou-se assim do desafio de realizar pesquisa etnográfica que, seguindo a perspectiva de Paul Willis, "reconhece e grava o modo como a experiência é entrelaçada no fluxo da história contemporânea” (WILLIS; TRONDMAN, 2008, p. 212).

Tendo essa configuração recente como referência, as conversas e entrevistas realizadas com as/os estudantes abordaram principalmente três processos de escolha: a escolha de fazer ensino superior, a escolha por um determinado curso e a escolha por uma IES. Para tanto, as trajetórias de vida (escolar, familiar, de 
trabalho, etc.), as expectativas futuras (qualificação profissional, trabalho, mobilidade social, sonhos, projetos) e as percepções sobre gênero constituíram-se como dimensões fundamentais para compreender narrativas sobre escolhas, dilemas e perspectivas.

\title{
A ESCOLHA POR PEDAGOGIA: DILEMAS DE INGRESSAR EM UM CURSO "POR AMOR"
}

\begin{abstract}
Sempre que você fala para alguém "vou fazer Pedagogia", sempre te falam "ai, mas você vai ser professora? Mas ninguém vai te valorizar". O Brasil ainda valoriza muito aquela trindade Engenharia, Medicina e Direito. [...] Então a gente é professora por amor, né? Não é por dinheiro não. (Daniela, estudante de Pedagogia)
\end{abstract}

O relato de Daniela ${ }^{9}$ expressa um sentimento frequente entre estudantes de Pedagogia com quem conversei. Em entrevista realizada na praça de alimentação da Faculdade 2, na terceira semana de aula, período noturno, Daniela aceitou participar mais ativamente da pesquisa e me contar em detalhes os porquês de suas escolhas. Pedagogia, segundo ela, é um curso que "se faz por amor, não por dinheiro".

Essa equação entre amor e dinheiro apareceu em diversas conversas e entrevistas, não apenas da área de Pedagogia, mas também em Enfermagem, e revela uma dimensão importante das tensões que tais escolhas representam. Ao acompanhar algumas estudantes de Pedagogia em suas interações on-line nas redes sociais, a hashtag ${ }^{10}$ "\#poramor" inclusive passou a ser frequente em suas publicações sobre o curso, revelando a centralidade que essa narrativa vocacional apresentava entre algumas estudantes.

Nessa conversa, Daniela retomou sua história de vida para refletir sobre a escolha por Pedagogia. Lembrou como seus pais fizeram grande esforço para lhe pagar uma escola particular desde o ensino infantil, localizada na região do Campo Limpo (zona sul de São Paulo). Quando ela estava entrando no ensino médio, seu pai, cuja profissão é motorista de ônibus, não estava mais conseguindo pagar a mensalidade. Sua mãe, atualmente de profissão auxiliar de limpeza, tampouco. As diretoras da escola então ofereceram à aluna a possibilidade de trabalhar como auxiliar de sala na educação infantil em troca de uma bolsa de estudos. Embora o trabalho com crianças pequenas tenha sido considerado difícil e cansativo, Daniela acabou gostando da experiência.

9 Daniela, 21 anos, solteira e sem filhos, autodeclarada parda. Nesse período estava desempregada.

10 Como parte do processo de comunicação em redes por meios digitais (MISKOLCl, 2016), o uso de hashtags disseminou-se recentemente nas redes sociais. Trata-se do uso do sinal gráfico \# antes da utilização de uma palavra-chave, conectando-a com todas as semelhantes por meio dos mecanismos de busca on-line. 
Quando terminou o ensino médio, já com expectativas pessoais e familiares de cursar o ensino superior (seria a primeira da família a ter tal titulação), Daniela teve dúvidas entre cursos de áreas muito diversas. Chegou a pensar em Física, mas percebeu que não tinha afinidades reais com a área de exatas. Posteriormente, acabou se decidindo por Publicidade, mas após um semestre cursado em outra IES privada não confessional viu que não era isso o que queria. Em fevereiro de 2017 finalmente decidiu-se por Pedagogia, matriculando-se na IES onde a conheci. Segundo sua narrativa, embora seus familiares estivessem felizes por seu ingresso no ensino superior - seu pai, principalmente, estava bastante orgulhoso por essa conquista -, a escolha por Pedagogia não se deu sem “decepções na família”. Conforme relato de Daniela:

Daniela: O sonho do meu pai é ter um filho graduado. Só que o sonho do meu pai era ter um filho graduado em Direito! Quando primeiro eu falei que queria fazer Física, ele achou lindo. Eu queria Física Computacional. Um nome lindo, maravilhoso, meu pai ficou feliz "achando que eu ia ser rica". Mal ele sabe que físicos, coitados, também não ficam ricos. Quando eu falei que ia fazer Pedagogia, ele falou "Filha, você tem que fazer alguma coisa que tenha nome! Faz Direito!" $E$ eu falei: "Deus me livre! Eu não nasci para defender bandido. Sai de mim! Não quero defender ninguém não!"

Pesquisadora: $E$ com essa expectativa toda do seu pai, você chegou a pensar em fazer Direito?

Daniela: Nunca! Nunca! Isso nunca passou pela minha cabeça. Nunca aconteceu de eu sentar assim e falar, "nossa, acho que vou fazer Direito!" [...] Mas agora meu pai está me apoiando, ele já aceitou que ele não manda [risos]. E ele está contente que estou na faculdade.

É interessante notar nessa narrativa o esforço por afastar-se da influência paterna, que se realizaria ao ver a filha cursando Direito, considerado por ele como o curso de maior prestígio desse esquema classificatório entre cursos superiores. Essa percepção, contudo, não condiz apenas com o pai de Daniela, mas trata-se de uma representação histórica do curso de Direito no Brasil, relacionado ao status do bacharel "doutor”. E quando se olha para as escolhas de alunos das escolas "fortes” da cidade de São Paulo, voltadas para o sucesso no vestibular, são os cursos de Direito, Medicina e Engenharia que ainda atraem os melhores estudantes (BANDERA, 2016). Contudo, fica o desafio de compreender por que, mesmo sabendo ser "desvalorizado" e indo contra a vontade de seus familiares, Daniela, entre tantas outras estudantes, decidem cursar (e "amar”) Pedagogia, tornando-o um dos maiores cursos superiores do país. Como compreender tais "narrativas vocacionais" levando a sério o que essas estudantes estão dizendo? 
Seguindo a trajetória relatada por Daniela, levar a sério essa narrativa, contudo, não implica relegar suas motivações "pragmáticas”. Daniela passou grande parte de sua adolescência trabalhando como auxiliar de sala em uma escola, experiência comum a quase todas as calouras de Pedagogia que conheci na primeira semana de aula, durante pesquisa etnográfica. Ou seja, nesse caso, o trabalho "na área" antecedeu a escolha do curso de ensino superior, fato comum entre jovens de menor renda - e diferente da trajetória mais comum entre jovens da classe média estabelecida, em que o ingresso no mundo do trabalho se dá posteriormente. Mas, nesse processo, o gosto pela área foi se desenvolvendo, conforme a própria Daniela narra.

Em pesquisa sobre a entrada de mulheres para o magistério nos anos de 1980, Cristina Bruschini e Tina Amado já se questionavam sobre tais discursos vocacionais que as estudantes proferiam, apesar da desvalorização e feminização da área de educação (BRUSCHINI; AMADO, 1988). Segundo questionamentos feitos por essas autoras: “Com tão poucas vantagens, como se explica que o magistério ainda seja visto como sacerdócio ou vocação?”. Empenhadas em desvendar tais narrativas e encontrar explicações para o fenômeno, as autoras concluíam:

Provavelmente porque a ideologia do amor e da dedicação tem justamente por função encobrir as condições concretas em que se dão as relações de trabalho. Esvaziando a carreira de seu conteúdo profissional, leva à quase inexistência de reivindicações de melhores salários e mais poder por parte da categoria. (BRUSCHINI; AMADO, 1988, p. 7)

Se a "quase inexistência de reivindicações" por melhores condições de trabalho na categoria poderia ser verdade nos anos de 1980, em 2018 essa não é a realidade, já que professores do ensino básico têm se mobilizado em constantes lutas e greves por reajuste salarial, melhores condições de trabalho e, recentemente, por reconhecimento de suas especificidades na discussão sobre a Reforma da Previdência. Assim, atualmente não se poderia afirmar a "inexistência de reivindicações” no setor. Contudo, Bruschini e Amado detêm parcela de razão, ao meu ver, ao mostrar como a íntima relação entre Pedagogia e gênero ainda encobrem diversas naturalizações sobre cuidado como algo eminentemente feminino e, portanto, mais desvalorizado, conforme discutirei adiante, após análise sobre as escolhas para ingresso no curso de Enfermagem.

Em pesquisa realizada já nos anos 2000, Claudio Nogueira e Flávia Pereira (2010) também se debruçaram sobre os discursos de escolha de curso entre estudantes de Pedagogia. Conforme pontuam os autores, nas teorias sociais sobre trajetórias educacionais e escolhas - diferentemente da área de orientação vocacional - é recorrente a conclusão de que as decisões tomadas por diferentes indivíduos não seriam expressões de um gosto autônomo; derivariam, ao contrário, das condições de sua realização. Nessa direção, tanto na perspectiva bourdieusiana quanto nas teorias da escolha racional, por exemplo, deparamos com 
visões desencantadas do mundo, em que as escolhas seriam tomadas em função de estratégias, sejam elas conscientes ou inconscientes. Retomando as análises de Pierre Bourdieu, conclui-se que "aprendemos a amar o que é possível ou mais provável” (2010, p. 16). Debruçando-se sobre tais questões, Nogueira e Pereira entrevistaram diferentes estudantes de perfil socialmente mais elevado do curso de Pedagogia da Universidade Federal de Minas Gerais (UFMG), analisando como constituíram um "gosto" especial pela área de educação. Concluíram que, por meio de uma análise atenta das trajetórias familiares e escolares de tais estudantes, desvendam-se caminhos complexos, que não podem ser reduzidos a explicações que compreendem o gosto como mero produto de uma adaptação dos agentes às suas posições sociais objetivas. Assim, enquanto algumas alunas escolheram Pedagogia porque de fato não haviam passado nos vestibulares de cursos mais prestigiosos, outras relataram um interesse genuíno pela área de educação. Desse modo, em alguns casos, "parece existir um gosto autêntico, que antecede o momento da escolha e que não se reduz a uma simples adaptação às condições objetivas" (NOGUEIRA; PEREIRA, 2010, p. 34).

Entre tais dilemas, também a estudante Aline, ${ }^{11}$ de 27 anos, conciliava narrativas de "resistência" e de "resignação" em sua escolha por Pedagogia. Em conversa na praça de alimentação da Faculdade 2, antes do início da aula das 19h, contou-me que quando criança, diante da clássica pergunta "o que você vai ser quando crescer”, não tinha nenhuma dúvida em dizer-se futura professora:

A Pedagogia já entrou na minha vida desde quando eu entrei na primeira série. Quando eu bati o olho na minha professora, eu falei pra minha mãe que eu ia ser igualzinha a ela. Eu sempre falei pra ela, pra todos os vizinhos, falava pra todo mundo que eu iria terminar a escola e ser professora. (Aline, estudante de Pedagogia)

Apesar do sonho, desde o início do ensino fundamental, de tornar-se professora, Aline foi se afastando dessa possibilidade antes de terminar o ensino médio, já que precisaria trabalhar de imediato para ter renda. Paralelamente, foi se distanciando daquele imaginário idealizado sobre "ser professora": "eu comecei a ouvir tanta gente dizendo que não valia a pena fazer Pedagogia que fui desistindo, sabe?”. Entre um dilema e outro, aos 22 anos Aline engravidou, afastando-se da possibilidade de logo cursar o ensino superior. Ela se casou, teve posteriormente mais uma filha, ficando anos trabalhando como dona de casa. Em 2017, no entanto, um impulso de estudar voltou, conforme Aline relata: "eu pensei, Meu Deus, não posso passar a vida só aqui dentro dessa casa! Vou estudar! Preciso estudar!”. Negociou então com o marido e parentes para decidir quem cuidaria de seus filhos de 3 e 6 anos enquanto estaria no curso. “Está sendo muito bom, sabe? Só 
pelo fato de estar aqui na faculdade já me sinto realizando um sonho". No entanto, Aline se preocupava com os desafios que teria pela frente:

Quando chegou a hora H, eu tive muita dúvida sobre escolher Pedagogia. Os salários, as condições pro professor dar aula, quase não têm apoio de ninguém... Elas estão praticamente abandonadas, lutando pelos seus direitos, além de ter que parar toda hora pra fazer greve. E o salário no estado é muito baixo pro trabalho que é. Até um professor nosso do curso falou esses dias "ou é por amor, porque você gosta mesmo, ou você vai se dar mal lá na frente! Se tem alguém aqui que escolheu Pedagogia de repente, porque não tinha outra opção, sai fora enquanto é tempo". Eu fiquei até balançada, com medo, mas eu gosto de verdade. (Aline, estudante de Pedagogia)

Conforme fica claro na fala de Aline, novamente a cobrança por uma aptidão verdadeira pela área de educação lhe foi exigida, nesse caso pelo professor universitário, que tentava alertar suas alunas sobre os desafios em relação à desvalorização crescente da carreira docente no Brasil em seus diferentes níveis. Ainda assim, Aline seguia adiante, esperançosa de que em breve poderia realizar seu sonho de, com dignidade, alfabetizar crianças.

Tanto no caso de Daniela quanto de Aline, fica evidente a busca por valorizar suas escolhas, ainda que estejam muito longe das condições de privilégio dos "herdeiros legítimos", portadores de alto capital cultural e econômico (BOURDIEU, 1998), tal qual os jovens universitários das classes médias e altas. Ambas serão as primeiras gerações de suas famílias a cursar ensino superior; para ambas, a universidade privada não confessional, mesmo que paga, foi vista como mais acessível, seja pela facilidade de ingresso, seja pela proximidade de suas residências. Pressionadas diante de escolhas difíceis, com pouca margem para erros, é que o ingresso no curso de Pedagogia pode ser ora interpretado como "resistência”, ora como "resignação".

\section{A ESCOLHA POR ENFERMAGEM: DILEMAS DE DEDICAR-SE AO CUIDADO DO OUTRO}

Na verdade eu sempre gostei de cuidar. Eu vim do Nordeste para cá, pra São Paulo, para trabalhar de babá. Agora trabalho como copeira, nada a ver, né? Mas nesse período eu descobri que Enfermagem era o meu sonho. (Andrea, estudante de Enfermagem) 
Na pesquisa de campo com estudantes de Enfermagem, também conversei com dois perfis de idade diferentes, mas recorrentes nesse universo: de um lado, estudantes jovens que saíram do ensino médio há pouco tempo (conforme idade considerada ideal pelas políticas educacionais, de 18 a 24 anos); de outro, estudantes adultas que decidiram retornar à sala de aula. Andrea ${ }^{12}$ se encaixa nesse segundo perfil. Tem 34 anos e conciliava o trabalho em período integral como copeira em uma empresa em Moema (bairro nobre de São Paulo) e a vida universitária, cursando Enfermagem no período noturno na Faculdade 2, desde o primeiro semestre de 2016.

Ao reconstituir sua trajetória educacional tortuosa, Andrea atribuía a decisão de abandonar a escola aos 12 anos à sua própria rebeldia. Segundo narrou, embora sua mãe fosse contra essa decisão, ela "queria ganhar dinheiro e viver a vida”. Em busca dessa autonomia, optou por deixar a família na Bahia e se mudar para São Paulo, indo residir na casa de sua futura patroa para trabalhar como babá. Aos 12 anos. Sobre isso ela diz: "eu não sei nem como tiveram coragem de me dar o bebezinho para cuidar, né? Eu também era uma criança!”. Após anos trabalhando como babá em diferentes casas, Andrea conseguiu um emprego como cuidadora de idosos, o que lhe permitiu voltar a estudar em um curso supletivo na capital paulista. Foi nesse emprego como cuidadora, já terminando o ensino médio, que Andrea teve uma "revelação": ao acompanhar uma idosa em uma internação no hospital, observou aquela rotina de enfermeiras e médicos e se encantou. Casada, mas sem filhos, Andrea pensou ali mesmo, naquele ambiente hospitalar: "acho que também posso mudar novamente de vida, quero fazer superior, quero ser enfermeira!". ${ }^{13}$ Estimulada pelas professoras do curso supletivo, prestou o Exame Nacional de Ensino Médio (Enem) por três anos, mas não conseguiu atingir a pontuação mínima para ingressar em universidade pública ou para obter uma bolsa do ProUni. Uma colega indicou o programa de bolsas de uma universidade privada, ela se cadastrou e conseguiu um desconto de $50 \%$ no curso de Enfermagem nessa IES, onde estava cursando desde o início de 2016.

Ao refletir sobre essas escolhas, e o porquê de Enfermagem, Andrea afirmava: "eu não tive dúvida ao escolher, tinha certeza que queria Enfermagem". Mas, em seguida, complementou: "Enfermagem era minha única opção”. Assim, nessa escolha de alternativa única, tanto em relação ao curso quanto em relação à instituição, evidenciavam-se alguns dos desafios de análise sobre escolhas no ensino superior brasileiro (NOGUEIRA, 2012). Se, por um lado, Andrea está longe da experiência da "universidade pública, gratuita e de qualidade" - tomada aqui como um possível ideal de experiência universitária -, por outro lado, ela própria interpretava sua chegada até ali como um ato de conquista. Afinal, sua trajetória até entrar naquela sala de aula não foi fácil, conforme ela própria interpretava:

\footnotetext{
12 Andrea, 34 anos, casada, sem filhos, autodeclarada negra. No período da pesquisa trabalhava como copeira.

13 Vale lembrar que essa experiência da "revelação" ou "chamado" (calling), revelando a "vocação" para a Enfermagem, está presente na trajetória de personagens importantes da história da Enfermagem, como a inglesa Florence Nightingale (1820-1910) ou a inglesa Madre Marie Domineuc, com importante trajetória na enfermagem brasileira (1911-1998) (RODRIGUES; SCHIRMER, 2010).
} 
Eu, pra te falar a verdade, estou muito feliz, me sinto muito confiante agora que estou estudando pra ser enfermeira. Eu gosto desse contato direto com as pessoas, de poder trabalhar no cuidado de pessoas que estão precisando, eu sou bem humana, assim. Vai ser uma realização. (Andrea, estudante de Enfermagem)

Se, por um lado, suas próprias narrativas sobre a escolha do curso e da instituição (escolhida em função da bolsa, porém longe de sua casa, já que ela reside no bairro de Parelheiros, extrema zona sul da cidade, levando duas horas no transporte público) revelam um campo de possibilidades restrito, por outro lado, trata-se do desafio de acompanhar as narrativas de estudantes como Andrea e ver quais os sentidos estão sendo atribuídos a essas diferentes etapas rumo ao diploma universitário.

No caso de Andrea, a trajetória profissional babá/cuidadora de idosos/ copeira/estudante de Enfermagem revelou uma inserção profissional marcada por aptidões "femininas" de cuidar, seja de bebês, idosos ou pessoas doentes. Nesse sentido é interessante retomar as reflexões que vêm sendo realizadas nas ciências sociais sobre os trabalhos de cuidado/care. Conforme pontuam Hirata, Guimarães e Sugita (2011, p. 156) “o care remete à questão de gênero, na medida em que essa atividade está profundamente naturalizada, como se fosse inerente à posição e à disposição (habitus) femininas”. No entanto, na perspectiva de Andrea, tais mudanças profissionais significaram um crescimento importante, a ser valorizado. Isso se torna mais nítido à medida que lembramos como o status de babá, empregada doméstica ou cuidadora de idosos ainda é precário e informalizado no mercado de trabalho brasileiro (HIRATA; GUIMARÃES; SUGITA, 2011; MACEDO, 2015). Nesse contexto, conforme aposta Andrea, o diploma de ensino superior na área de enfermagem tornava-se bastante promissor para "mudar de vida" e crescer profissionalmente.

A trajetória da estudante Cássia, ${ }^{14}$ de 39 anos, também se revelou interessante para observar esse processo de retorno aos estudos em fase adulta, apontando paralelos com a estudante de Pedagogia Aline, apresentada anteriormente. No caso de Cássia, a principal justificativa para o afastamento de mais de uma década das salas de aula foi a criação e os cuidados com o filho:

Eu demorei pra fazer a faculdade. Mas eu também demorei pra fazer o técnico porque eu fui ter meu filho [que agora tem 18 anos], eu fui dando prioridade pro meu filho... Eu estava sem condições... Eu inverti: ao invés de ir pra profissão e depois pra família, eu fui primeiro pra família e depois eu

14 Cássia, 39 anos, casada, um filho, autodeclarada branca. No período, trabalhava como técnica de enfermagem em um grande hospital privado em São Paulo. 
Nesse caso, assim como em outros narrados ao longo da pesquisa, casamento e filhos aparecem como o principal motivo de afastamento dos estudos. Claramente ser mulher a diferencia nesse processo, já que gênero teve impacto direto nessa decisão de "cuidar" enquanto seu marido "trabalhava". Contudo, se ela, assim como outras estudantes pesquisadas, retornou aos estudos, os maridos dessas interlocutoras de pesquisa não tiveram a mesma motivação, contentando-se com suas qualificações adquiridas na juventude. A análise qualitativa de experiências como essa torna-se, inclusive, interessante para formularmos algumas hipóteses sobre a persistente maioria de mulheres no ensino superior brasileiro desde o censo de 1991 (RIBEIRO; SCHLEGEL, 2015). No caso de Cássia, se em um primeiro momento ela contava com o dinheiro do trabalho de seu marido para manter a casa que ela cuidava, no período recente a situação tinha se invertido: ele estava desempregado e ela, com seu salário enquanto técnica de enfermagem, sustentava todos os integrantes da casa e ainda pagava a mensalidade da faculdade.

Sobre a escolha de Cássia pelo curso de Enfermagem, sua narrativa remetia à história familiar e à experiência profissional prévia enquanto técnica de enfermagem:

\begin{abstract}
A minha mãe trabalha nessa área, talvez tenha sido um pouco influência dela [que é auxiliar de enfermagem]. Ela nunca me falou assim: "faça Enfermagem", mas acho que eu me identifiquei. Mas esse trabalho não é fácil, não é fácil não, olha minha cara, eu tô exausta, é correria todo o tempo [na UTI do hospital]... Mas eu gosto. Tem o lado bom e tem o lado ruim. Mas eu gosto de estar ali, eu preciso estar ali, por isso que eu decidi fazer a faculdade. (Cássia, estudante de Enfermagem)
\end{abstract}

Nota-se, nessa narrativa, como tal escolha foi bastante ponderada. Diferente de Andrea, que ainda não tinha trabalhado na área, Cássia já enfrentava há anos a rotina pesada de um grande hospital (trabalhando diariamente das $6 \mathrm{~h}$ às $14 \mathrm{~h}$ ), além de já estar previamente familiarizada pelas experiências profissionais da mãe. Cursar o ensino superior, no seu caso, significava uma chance importante de continuar nessa trajetória, mas com maior qualificação, superando os trabalhos mais manuais e exaustivos associados às técnicas de enfermagem, como a troca e banho dos pacientes internados. No entanto, ao refletir sobre essa sua decisão, Cássia lembrava do que seria seu "verdadeiro sonho" - o curso de Veterinária: 
fazer Veterinária. O valor do curso é muito alto. Depois, eu já estava pensando lá na frente em ter um consultório, em competir com um monte de gente que tem dinheiro. Porque além de você ter que ter dinheiro pra ter o seu próprio pet shop, você tem que competir com milhões que o mercado já tem. Ai eu acabei desistindo... Mas Enfermagem eu também gosto... (Cássia, estudante de Enfermagem)

Assim, Cássia revela em sua narrativa os ajustes de expectativas entre o que se pode ou não escolher a partir de diferentes lugares sociais. Se, conforme pontua Gilberto Velho (2013, p. 67), os projetos individuais seriam "resultado de uma deliberação consciente a partir das circunstâncias, do campo de possibilidades em que está inserido o sujeito", nesse caso, Enfermagem foi a "escolha possível” para Cássia naquele momento. Veterinária, ao contrário, lhe parecia estar fora do seu campo de possibilidades, tanto pelo custo mais alto da mensalidade de graduação (cerca de R 1.500 na Faculdade 1, três vezes superior ao valor que ela pagava em 2017 com bolsa de estudos pelo curso de Enfermagem), quanto pela visão da dificuldade posterior para montar seu próprio negócio. Ainda assim, seu trabalho diário na UTI de um hospital, somado à sua persistência em "seguir nos estudos" e fazer o superior na área, dão a Cássia a confiança de ter optado por uma carreira profissional considerada por ela "bonita" e "importante", enredando, outra vez, sentimentos de "resistência" e "resignação" nessa escolha. Acompanhar pelo grupo de WhatsApp as fotos da primeira vez em que algumas estudantes de sua turma vestiram o avental branco para a primeira aula de laboratório, emocionadas, evidenciou alguns desses sentimentos ambivalentes que acompanham tais escolhas.

\section{GÊNERO, FEMINILIDADES E CUIDADO ENTRE ESTUDANTES DE PEDAGOGIA E ENFERMAGEM}

De todos os cursos de ensino superior brasileiros na atualidade, Pedagogia e Enfermagem estão entre os que mantêm maior homogeneidade por gênero, concentrando maioria de estudantes mulheres [92\% das estudantes de Pedagogia e 85\% das de Enfermagem (BRASIL, 2015)]. Conforme pontuavam Cristina Bruschini e Tina Amado (1988), nos anos de 1980, professoras, ao lado de enfermeiras e secretárias, constituem "guetos femininos" no mercado de trabalho.

O estudo pioneiro de Carmen Barroso e Guiomar Mello sobre o "acesso da mulher ao ensino superior" (de 1975) é revelador da constituição histórica dessa dinâmica. Ao comparar dados sobre a década de 1950 com a de 1970, as autoras constatavam como a entrada de mulheres nessa etapa de ensino era cada vez mais expressiva - representavam $26 \%$ dos estudantes universitários em 1956 e $40 \%$ em 1970. Porém, esse acesso se dava de modo muito desigual entre os diferentes cursos analisados: "verifica-se até um aumento de concentração das alunas em algumas poucas carreiras 'femininas' que, definidas culturalmente como 
mais apropriadas à mulher, têm tido tradicionalmente uma predominância de mulheres entre seus alunos" (BARROSO; MELLO, 1975, p. 52). Assim, enquanto alguns cursos como Magistério Secundário, Enfermagem e Serviço Social eram vistos nos anos de 1970 como plenamente "femininos", cursos como Direito começavam a apresentar algumas mudanças, progressivamente atraindo mais mulheres (25\% em 1971). Entre as explicações para o fenômeno ofertadas no texto, já encontramos as hierarquias e status socialmente estabelecidos entre os diplomas (BARROSO; MELLO, 1975).

A questão se torna ainda mais interessante se lembrarmos que, conforme contextualiza Guacira Lopes Louro (2001), a Pedagogia no Brasil, como em outros países, inicialmente foi considerada um trabalho de homens - religiosos, jesuítas, oficiais, professores. No século XIX, a abertura das Escolas Normais para a formação de professores passou a recrutar aprendizes de ambos os sexos e, assim, pouco a pouco, a oportunidade passou a atrair mais mulheres do que homens. Esse movimento, segundo Louro, daria origem à "feminização do magistério", fenômeno histórico "vinculado ao processo de urbanização e industrialização que ampliava as oportunidades de trabalho para os homens" (LOURO, 2001, p. 449). Progressivamente, o magistério passou a ser associado a uma atividade de amor, entrega e doação, recrutando aquelas mulheres que tivessem tal "vocação". Segundo Guacira Louro, se tal associação com o universo feminino hoje parece “tão natural”, na época gerou muitas disputas e polêmicas. Pouco a pouco, entretanto, o argumento de que o magistério seria afeito ao trabalho doméstico e à maternidade foi se naturalizando.

Também a Enfermagem, segundo Maria Lúcia Mott (1999), tornou-se no Brasil uma profissão “de mulheres” na virada do século XIX para o XX; antes, enfermeiros homens e mulheres dividiam funções, muitas vezes assumindo a enfermaria "correspondente ao seu sexo". À medida que foram surgindo as primeiras escolas de Enfermagem, estas passaram a recrutar apenas mulheres, em sua maioria religiosas; esse foi o caso do Hospital Samaritano, fundado em $1894 \mathrm{em}$ São Paulo: não aceitavam enfermeiras casadas, e as solteiras não podiam receber visitas de "moços solteiros" (MOTT, 1999, p. 341). Nesse momento, a profissão passou a ser associada com características consideradas inerentes às mulheres: paciência, carinho, cuidado, abnegação, dedicação, servidão. ${ }^{15}$ Para além de uma escolha profissional, valorizou-se também nesse campo a ideia da "vocação", narrativa destacada desde o século XIX por uma das fundadoras da Enfermagem Moderna, a inglesa Florence Nightingale, que dizia ter recebido um "chamamento" para a profissão aos 17 anos (RODRIGUES; SCHIRMER, 2010).

$\mathrm{Na}$ atualidade, se diversos cursos superiores apresentaram mudanças significativas em relação à gênero - como Medicina e Direito, inicialmente formado por estudantes homens, tornando-se cada vez mais femininos (RIBEIRO; 
SCHLEGEL, 2015) -, Enfermagem e Pedagogia se mantiveram fortemente marcados pela maior homogeneidade de gênero ao longo do século XX e início do XXI.

Para interpretar essa persistente presença massiva de mulheres em algumas áreas profissionais no Brasil, é comum a mobilização da perspectiva da “divisão sexual do trabalho". Na Enfermagem, conforme constatam Marta Lopes e Sandra Leal (2005, p. 105), persiste a feminização "tanto na qualificação universitária como nos níveis médio e técnico”; tal processo está ligado, segundo as autoras, à divisão sexual do trabalho, entendida como "um princípio organizador da sociedade capitalista”, o qual se associa a outras formas de divisão social do trabalho. Assim, no caso das profissões feminizadas da saúde, mantém-se a relação entre "cuidado" e "ação feminina”, num processo que naturaliza essas diferenças como atribuídas ao sexo feminino (LOPES; LEAL, 2005).

Também na Pedagogia a noção de “divisão sexual do trabalho" é frequentemente mobilizada para compreender a grande concentração de mulheres na área. Em pesquisa sobre gênero e trabalho docente, Claudia Vianna e Carolina Alvarenga (2012) concluem, no entanto, que a simples oposição entre trabalho produtivo/masculino versus trabalho reprodutivo/feminino apresentava algumas limitações, apontando para situações mais complexas. Segundo as autoras, ao analisar o uso do tempo entre mulheres e homens dedicados à carreira docente, percebe-se que "as vivências e os significados do trabalho docente são diversos daqueles previstos pelas teorias da divisão sexual do trabalho, por serem múltiplas as preocupações, os interesses e os projetos" (VIANNA; ALVARENGA, 2012, p. 23).

Neste artigo, a partir da pesquisa apresentada, destaco que embora as análises sobre divisão sexual do trabalho sejam fundamentais para a compreensão do persistente processo de feminização de algumas áreas educacionais e profissionais (HIRATA; KERGOAT, 2007), trata-se também de compreender “quais feminilidades” estão sendo progressivamente mobilizadas para tanto, seja em corpos do sexo feminino ou masculino (MOORE, 2000; CONNELL, 2016). ${ }^{16}$ Conforme pontua Henrietta Moore (2000, p. 31), múltiplas feminilidades e masculinidades se constituem discursivamente, de modos ambivalentes e contraditórios, em um “jogo paródico”, ora reiterando, ora desafiando os discursos dominantes. Nesse sentido, torna-se possível refletir sobre quais atributos e características "femininas” podem contextualmente ser considerados mais convenientes para a regulação de certas atividades profissionais.

Embora atualmente tais naturalizações do que seria eminentemente feminino pareçam datadas e anacrônicas, a cristalização entre “cuidar” e ser "mulher”, seja na Enfermagem, seja na Pedagogia, revela-se ainda muito forte, inclusive entre as estudantes que participaram da pesquisa aqui apresentada. Quando, nas conversas e entrevistas, eu explicitava meu interesse no tema, diferentes 
narrativas reforçaram a associação entre mulheres e o trabalho de cuidado com crianças ou idosos:

\begin{abstract}
Eu sei que isso é meio complicado, mas eu acho que a muIher tem mais jeito com criança. Pode ver, não tem quase nenhum professor homem na educação infantil, não tem. $E$ na nossa sala, só tem um homem! É uma coisa mais de muIher mesmo. (Thais, ${ }^{17}$ estudante de Pedagogia)

É porque é uma profissão meio feminina mesmo... Mas é complicado falar isso. Por exemplo, a gente tem que tirar a roupa dos pacientes, dar banho... Porque mesmo se o paciente for um homem, pode ser que ele tenha vergonha, mas ele sabe que a enfermeira mulher vai ajudar. [reflete um pouco] Mas eu acho que isso tem mais a ver com a história mesmo, como a profissão começou com mulheres, agora é que os homens estão descobrindo que é uma área boa pra eles também. (Luana, ${ }^{18}$ estudante de Enfermagem)
\end{abstract}

Nas falas de Thais e Luana que reiteravam alguns estereótipos de gênero, expressava-se também a realidade vivenciada em suas salas de aula na Faculdade 2: na sala de Thais, do curso de Pedagogia, tinha apenas um homem entre 65 ingressantes (que logo desistiu); já na turma de Luana, de cerca de 30 ingressantes, 6 eram homens. No entanto, ao retomar alguns aspectos históricos sobre a feminização da Enfermagem no Brasil, Luana apontava para algumas mudanças possíveis, que progressivamente questionam tais cristalizações entre cuidar e ser mulher.

Assim, de modo geral, ao longo desta pesquisa, reiterava-se uma constatação presente em diversos estudos sobre gênero no ensino superior: licenciaturas, como Pedagogia, seguem sendo redutos femininos e com pouco reconhecimento social, especialmente quando comparadas a outras áreas, como as engenharias - redutos masculinos e socialmente mais valorizados (CASAGRANDE; SOUZA, 2017). De modo similar, profissões ligadas ao cuidar, como Enfermagem, ainda estão naturalizadas no senso comum como sendo "naturalmente" mais femininas.

Além da constatação de que tais cursos seguem reunindo quase que exclusivamente mulheres em sala de aula, trata-se também do desafio de analisar “quais noções de feminilidade são mobilizadas e requeridas” nessas áreas profissionais. A conversa que tive com a estudante de Pedagogia Daniela foi expressiva desse processo de seleção de uma “feminilidade ideal” para a área profissional,

\footnotetext{
17 Thais, 19 anos, solteira, sem filhos, autodeclarada branca. No período, trabalhava como auxiliar de sala em escola privada de ensino infantil.

18 Luana, 25 anos, solteira, sem filhos, autodeclarada negra. No período, trabalhava como inspetora de sala em uma escola pública.
} 
constituída de modo ambíguo por diferentes agentes (professoras e professores, coordenadores, estudantes, mídia, etc.):

A coordenadora disse para nós logo no começo do curso que temos que aprender a ser professoras pelo olhar idealizado da criança. A estudante de Pedagogia, segundo nos disseram já na primeira semana, não bebe, não fuma, não namora, não fala palavrão e não passa no sinal vermelho. Para os alunos somos princesas da Disney! É dureza ter que ouvir isso logo de cara, né? (Daniela, estudante de Pedagogia)

A fala crítica de Daniela é interessante, já que na convivência com as estudantes, percebe-se que as alunas ora se afastam, ora se aproximam desse imaginário da "feminilidade ideal" para a Pedagogia ou para Enfermagem. Conforme pontua Butler (2014, p. 272), podemos pensar sobre tais discursos como regulações engajadas "em produzir e manter a norma sobre o que um homem ou uma mulher devem ser, o que a linguagem deve ser, onde a sexualidade estará e não estará". Tais reiterações também são apreensíveis nas cenas cotidianas. Caminhando pelos corredores da Faculdade 2 com a estudante Thais, ao ver uma estudante de outro semestre passar de blusa curta, com a barriga de fora, ela me dizia: "tem roupa de vir na faculdade e roupa de ir na balada, você não acha? Essas meninas não têm noção...”. Nessas pequenas cenas, percebe-se como normas de gênero se expressam e se estabelecem, constituindo os atributos ideais para a "mulher pedagoga" e a "mulher enfermeira”. Entretanto, essas mesmas estudantes questionam por vezes algumas dessas regulações, também vestindo blusas curtas, aproveitando os barzinhos do entorno da faculdade ou mesmo vivenciando novas experiências afetivo-sexuais.

Se, como vimos, do ponto de vista dos discursos regulatórios, não é qualquer atributo feminino que é considerado ideal para seguir em tais cursos superiores, tampouco qualquer homem pode se constituir como pedagogo ou enfermeiro com facilidade. Conforme conversas que tive a esse respeito com algumas estudantes (e fofocas que acompanhei) sobre o único homem presente na turma de ingressantes de Pedagogia, esperava-se que ele fosse gay, aproximando-o dos espaços de feminilidade e, assim, das habilidades vistas como ideais para o cuidar, tais como paciência, afeto e sensibilidade. $\mathrm{Na}$ convivência com algumas estudantes da Enfermagem, também se debatia entre cochichos a sexualidade dos poucos rapazes, mobilizando diferentes associações entre cuidado e feminilidades. Por outro lado, alguns atributos considerados masculinos, como força física, eram valorizados entre os homens "menos femininos", especialmente porque tais características podem ser valorizadas no mercado de trabalho da enfermagem. Conforme refletia a estudante Luana: "tem muito paciente pesado e homem é mais forte. Tipo, se for uma entrevista de emprego num hospital, e for eu e um homem, com certeza ele vai passar e não eu, porque tem poucos homens formados e eles precisam de enfermeiros fortes”. Nesse caso, mais uma vez, 
diferenças de gênero tornavam-se uma desvantagem para as mulheres, conforme interpretação de Luana, mesmo em uma profissão feminilizada.

\section{CONSIDERACCÕES FINAIS}

A pesquisa aqui apresentada discute os processos de escolha para ingresso no ensino superior, focalizando as experiências de estudantes dos cursos de Enfermagem e Pedagogia em duas instituições privadas não confessionais localizadas na cidade de São Paulo. Por meio de conversas e entrevistas com estudantes mulheres jovens e adultas, destacou-se a importância de enfatizar os matizes de gênero envolvidos nessas escolhas profissionais, além da articulação com outros marcadores sociais da diferença, como classe social e idade. As trajetórias e narrativas destacadas ao longo do artigo demonstram como atributos intimamente associados às áreas de pedagogia e enfermagem - como paciência, afeto, cuidado e abnegação - seguem sendo vistos como mais femininos que masculinos. No entanto, para além da constatação de que Pedagogia e Enfermagem ainda são áreas plenamente feminizadas, torna-se importante refletir sobre uma maior pluralidade de feminilidades produzidas e reproduzidas nesses processos educacionais e profissionais.

De modo geral, o artigo ressalta a importância de se olhar para as escolhas para ingresso no ensino superior de maneira matizada, levando simultaneamente em conta as "narrativas pragmáticas" (facilidade de acesso, oportunidades no mercado de trabalho, valor da mensalidade) e as "narrativas vocacionais" (aptidão, habilidades, sonhos, “amor” à área). Trata-se, assim, do desafio de levar a sério o que as próprias estudantes estão dizendo, com todas as suas contradições e ambivalências.

Em um contexto político-econômico nacional e internacional cada vez mais incerto, marcado por um capitalismo flexível e instável, registra-se ainda como as estudantes pesquisadas enfrentam o desafio de conciliar expectativas de mobilidade social, valorização profissional e realização pessoal. Como aponta François Dubet (2014, p. 143), paralelo à progressiva acentuação do individualismo na contemporaneidade, intensifica-se também o desejo por "experimentar o sentimento de se realizar". Assim, embora compreender as "escolhas do destino" determinadas pela posição social de gênero, classe social, raça e idade sejam fundamentais para a análise de trajetórias nas ciências sociais (BOURDIEU, 1998), não podemos relegar as narrativas de afeto e resistência para segundo plano. No caso das estudantes de Enfermagem e Pedagogia aqui apresentadas, suas narrativas apontam para o desafio de, por um lado, resignar-se à realidade nacional que não valorizará social e financeiramente seus diplomas do mesmo modo que os diplomas de outras áreas; por outro lado, trata-se do desafio de resistir e lutar pela valorização de áreas socialmente fundamentais, mas ainda vistas como femininas e menos importantes à sociedade brasileira. 
ALMEIDA, Wilson. Os herdeiros e os bolsistas do ProUni na cidade de São Paulo. Educação e Sociedade, Campinas, v. 36, n. 130, p. 85-100, mar. 2015

BANDERA, Nicolau Dela. A escolha da tradição: o campo dos possíveis para os estudantes do IFSP. Educação e Realidade, Porto Alegre, v. 41, n. 3, p. 809-832, 2016.

BARBIERI, Márcia; RODRIGUES, Jaime. Memórias do cuidar: setenta anos da Escola Paulista de Enfermagem. São Paulo: Editora Unifesp, 2010.

BARROSO, Carmen Lucia de Melo; MELLO, Guiomar. O acesso da mulher ao ensino superior brasileiro. Cadernos de Pesquisa, São Paulo, v. 15, p. 47-77, dez. 1975.

BOURDIEU, Pierre. A escola conservadora: as desigualdades frente à escola e à cultura. In: NOGUEIRA, Maria Alice; CATANI, Afrânio (org.). Escritos de educação. Petrópolis: Vozes, 1998.

BRASIL. Ministério da Educação. Instituto Nacional de Estudos e Pesquisas Educacionais Anísio Teixeira. Apresentação - Censo da Educação Superior 2015. 2015. Disponível em: http://download.inep.gov.br/ educacao_superior/censo_superior/apresentacao/2015/Apresentacao_Censo_Superior_2015.pdf. Acesso em: 15 out. 2016.

BRASIL. Ministério da Educação. Instituto Nacional de Estudos e Pesquisas Educacionais Anísio Teixeira. Apresentação - Censo da Educação Superior 2016. 2016. Disponível em: http://portal.inep.gov. br/artigo/-/asset_publisher/B4AQV9zFY7Bv/content/mec-e-inep-divulgam-dados-do-censo-da-educacaosuperior-2016/21206. Acesso em: 3 set. 2017.

BRUSCHINI, Cristina; AMADO, Tina. Estudos sobre mulher e educação: algumas questões sobre o magistério. Cadernos de Pesquisa, São Paulo, n. 64, p. 4-13, fev. 1988.

BUTLER, Judith. Regulações de gênero. Cadernos Pagu, Campinas, v. 42, p. 249-274, jan./jun. 2014.

CASAGRANDE, Lindamir; SOUZA, Ângela. Percorrendo labirintos: trajetórias e desafios de estudantes de engenharias e licenciaturas. Cadernos de Pesquisa, São Paulo, v. 47, n. 163, p. 168-200, jan./mar. 2017.

CONNELL, Raewyn. Gênero em termos reais. São Paulo: Versos, 2016.

COSTA, Henrique Bosso. Entre o lulismo e o ceticismo: um estudo de caso com prounistas em São Paulo. 2015. Dissertação (Mestrado em Ciência Política) - Universidade de São Paulo, São Paulo.

DUBET, François. Injustiças: a experiência das desigualdades no trabalho. Florianópolis: Editora UFSC, 2014. HIRATA, Helena; KERGOAT, Danièle. Novas configurações da divisão sexual do trabalho. Cadernos de Pesquisa, São Paulo, v. 37, n. 132, p. 595-609, set./dez. 2007.

HIRATA, Helena; GUIMARÃES, Nadya; SUGITA, Kurumi. Cuidado e cuidadoras: o trabalho do Care no Brasil, França e Japão. Sociologia \& Antropologia, Rio de Janeiro, v. 1, n. 1, p. 151-180, jan.jjun. 2011.

INSTITUTO DE PESQUISA ECONÔMICA APLICADA - IPEA. Radar: tecnologia, produção e comércio exterior. N. 27 - Especial Perspectivas profissionais - níveis técnico e superior. 2013. Disponível em:

http://repositorio.ipea.gov.br/bitstream/11058/3485/1/Radar_n27.pdf. Acesso em: 30 mar. 2017.

KOPPER, Moisés; DAMO, Arlei. A emergência e evanescência da nova classe média brasileira. Horizontes Antropológicos, Porto Alegre, v. 24, n. 50, p. 335-376, jan./abr. 2018.

LAHIRE, Bernard. Sucesso escolar nos meios populares: as razões do improvável. São Paulo: Ática, 2004.

LOPES, Marta; LEAL, Sandra. A feminização persistente na qualificação da enfermagem brasileira. Cadernos Pagu, Campinas, v. 24, p. 105-125, 2005.

LOURO, Guacira Lopes. Mulheres na sala de aula. In: PRIORE, Mary. História das mulheres no Brasil. São Paulo: Editora Unesp; Contexto, 2001.

MACEDO, Renata Mourão. Trabalhadoras e consumidoras: transformações do emprego doméstico na sociedade brasileira. Política \& Trabalho: Revista de Ciências Sociais, n. 42, p. 311-333, jan./jun. 2015. 
MISKOLCI, Richard. Sociologia digital: notas sobre pesquisa na era da conectividade. Revista Contemporânea, São Carlos, v. 6, n. 2, p. 275-297, 2016.

MOORE, Henrietta. Fantasias de poder e fantasias de identidade: gênero, raça e violência. Cadernos Pagu, Campinas, n. 14, p. 13-44, 2000.

MOTT, Maria Lúcia. Revendo a história da enfermagem em São Paulo (1890-1920). Cadernos Pagu, Campinas, n. 13, p. 327-355, 1999.

NOGUEIRA, Claudio. Escolha racional ou disposições incorporadas: diferentes referenciais teóricos na análise sociológica do processo de escolha dos estudos superiores. Revista Estudos de Sociologia, Recife, v. 2, n. $18,2012$.

NOGUEIRA, Claudio; PEREIRA, Flávia. O gosto e as condições de sua realização: a escolha por pedagogia entre estudantes com perfil social e escolar mais elevado. Educação em Revista, Belo Horizonte, v. 26, n. 3, dez. 2010.

PEREIRA, Alexandre. Do controverso "chão de escola" às controvérsias da etnografia: aproximações entre antropologia e educação. Horizontes Antropológicos, Porto Alegre, v. 23, n. 49, p. 149-176, set./dez. 2017.

RIBEIRO, Carlos Antonio Costa; SCHLEGEL, Rogerio. Estratificação horizontal e ensino superior no Brasil (1960 a 2010). In: ARRETCHE, Marta (org.). Trajetórias de desigualdades: como o Brasil mudou nos últimos cinquenta anos. São Paulo: Editora Unesp, 2015.

RODRIGUES, Jaime; SCHIRMER, Janine. Enfermagem: uma profissão feminina? O caso do curso de enfermagem da Universidade Federal de São Paulo. In: BARBIERI, Márcia; RODRIGUES, Jaime. Memórias do cuidar: setenta anos da Escola Paulista de Enfermagem. São Paulo: Editora Unifesp, 2010.

SAMPAIO, Helena. Diversidade e diferenciação no ensino superior no Brasil: conceitos para discussão. Revista Brasileira de Ciências Sociais, São Paulo, v. 29, n. 84, p. 43-55, fev. 2014.

SALDAÑA, Paulo; BOLDRINI, Angela. Total de matrículas no ensino superior tem estagnação inédita em 2016. Folha de S.Paulo, 31/08/2017. Disponível em: https://www1.folha.uol.com.br/educacao/2017/08/1914492total-de-matriculas-no-ensino-superior-tem-estagnacao-inedita-em-2016.shtml?loggedpaywall. Acesso em: 1 set. 2017.

VELHO, Gilberto. Um antropólogo na cidade. Rio de Janeiro: Zahar, 2013.

VIANNA, Claudia; ALVARENGA, Carolina. Relações sociais de gênero e divisão sexual do trabalho: desafios para a compreensão do tempo de trabalho docente. Revista Laboreal, Porto, v. 8, n. 1, p. 11-27, jul. 2012.

WILLIS, Paul. Aprendendo a ser trabalhador: escola, resistência e reprodução social. Porto Alegre: Artes Médicas, 1991.

WILLIS, Paul; TRONDMAN, Mats. Manifesto pela etnografia. Revista Educação, Sociedade e Culturas, n. 27, p. 211-220, 2008.

YANNOULAS, Silvia. Feminização ou feminilização? apontamentos em torno de uma categoria. Temporalis, Brasília, v. 11, n. 22, p. 271-292, 2011.

\section{COMO CITAR ESTE ARTIGO}

MACEDO, Renata Mourão. Resistência e resignação: narrativas de gênero na escolha por enfermagem e pedagogia. Cadernos de Pesquisa, São Paulo, v. 49, n. 172, p. 54-76, abr.jjun. 2019. https://doi.org/10.1590/198053145992 
